\title{
Prevalence and factors associated with thinness among adolescent girls attending high schools in rural and urban high schools of Soro District, Hadiya Zone, Southern Ethiopia
}

\author{
Denebo Akiso \\ Wachamo University \\ Tefera Belachew \\ Jima University \\ Tegegn Arficho ( $\nabla$ tegegntadesse24@gmail.com ) \\ Wachamo University \\ Beakal Zinab \\ Jima University
}

\section{Research Article}

Keywords: Thinness, adolescents, Girls, Ethiopia, High school, prevalence, factors

Posted Date: November 5th, 2021

DOl: https://doi.org/10.21203/rs.3.rs-956535/v1

License: (c) (i) This work is licensed under a Creative Commons Attribution 4.0 International License.

Read Full License 


\section{Abstract \\ Background}

Despite the government of Ethiopia is striving to reduce the prevalence of the undernutrition, thinness among adolescents is one of the challenging nutritional issues in lifecycle approach in Ethiopia. Therefore, this study was aimed on determining the prevalence of thinness and its associated factors among adolescent girls attending high schools in Soro District, Hadiya Zone, Southern Ethiopia.

\section{Methods}

Institution based comparative cross sectional study design was employed. The study was conducted from March 15 to April 15, 2019 in high schools of rural and urban settings of Sorro District, Hadiya Zone. Both binary and multivariable logistic regression analysis were done to identify the factors associated with thinness among adolescent girls.

\section{Result}

A total of 414 adolescent girls were participated in this study making the response rate of $100 \%$. The mean age were (17.01 \pm 1.55$)$ and $16.90 \pm 1.48, P=0.437)$ among adolescent girls in rural and urban high schools respectively. The overall prevalence of the thinness among female adolescents attending high schools in Soro district, Hadiya Zone was $6.8 \%$. There was no statistically significant difference in thinness among adolescent girls in rural and urban high schools. Household wealth tertile AOR: 4.19; $95 \%$ C.I: 1.13-15.47, $\mathrm{P}<0.05$, source of drinking water AOR: $2.31 ; 95 \%$ C.I: $1.01-5.30, \mathrm{P}<0.05$, dietary diversity AOR: 3.99; C.I: 1.15-13.82, $P<0.05$ and skipping breakfast AOR: 2.97; C.I: 1.28-6.92, $P<0.05$ were found to be independent factors associated with thinness.

\section{Conclusion}

Being low in household wealth tertile, unprotected source of drinking water, inadequate dietary diversity and skipping breakfast were those factors identified to be independently associated with thinness among female adolescents. Attention should be given from government and nongovernmental organizations by empowering household economic capacity, extending access for pure drinking water and increasing nutrition sensitive agriculture focusing on maintaining food varieties.

\section{Background}

World Health Organization (WHO) defines adolescences as individuals in the age groups of 10-19 years of age and it is the transition period that lies between childhood and adulthood [1]. Adolescence is the second most rate of growth period regarding physical growth in life cycle after infants, due to this their 
nutritional needs are high and accompanied by the gradual development of reproductive organs, secondary sexual characteristics and menarche in girls [2]. Poor nutrition occurred at this stage span across generations, affecting all stages of the life cycle [3]. They are nutritionally vulnerable for a number of specific reasons including their high nutrients requirements for their rapid growth rate, their eating patterns lifestyles, their risk-taking behaviors and their susceptibility to environmental influences [1]. The vast majority of adolescents, 90 percent, live in low and middle-income countries (LMICs). In 2016, 25\% of the total population was represented by adolescents in Ethiopia [4].

WHO recommend the new WHO Growth Reference to measure thinness among adolescent by using body mass index-for-Age (BAZ) indices. Accordingly, those with BAZ (BMI for age Z-score) less than -2SD are categorized under thinness [5]. Globally, the prevalence of thinness among adolescent girls was $8.4 \%$ and the trends of prevalence of thinness decreased from 9.2\% in 1975 to 8.4\% in 2016 [6]. However, the prevalence of thinness is highest in south Asia and Africa which were $41 \%$ and $12.5 \%$, respectively [7]. Despite the government of Ethiopia is striving to reduce the prevalence of the undernutrition, thinness among adolescents is one of the challenging nutritional issues in lifecycle approach in Ethiopia. Besides the attention is given on reducing the prevalence of the undernutrition among children even if the adolescence period needs nutritional priority to break the intergenerational cycle of undernutrition.

Few studies were conducted to find out the prevalence of the thinness among adolescent girls and factors associated with thinness among adolescents in Ethiopia generally and in the study area particularly. It needs to undertake studies to fill the information gap according to thinness among adolescent girls that is helpful for program planers and policy makers on adolescent nutrition. Hence, this study was aimed on determining the prevalence of thinness and its associated factors among adolescent girls attending high schools in Soro District, Hadiya Zone, Southern Ethiopia.

\section{Methods}

\section{Study area and design}

Sorro District is located in Hadiya zone, Southern regional state of Ethiopia. Geographically, it is situated at $32 \mathrm{Km}$ South-East of Hossana that is the capital city of Hadiya Zone and $264 \mathrm{Km}$ away from Addis Ababa, the capital city of Ethiopia. Main economic activity of the rural district peoples depend on agricultural products mainly teff, wheat, inset, barley, corn, bean, pea and domestic animals. Besides, the main economic activity in urban area is market oriented business activities and civil servants services [8].

The study was conducted from March 15 to April 15, 2019 in high schools of rural and urban settings of Sorro District, Hadiya Zone. Institution based comparative cross sectional study design was employed.

\section{Study population}

All adolescent girls attending high schools at rural and urban settings of Sorro district were the source population of the study while those adolescent girls selected randomly for the study were the study 
population. All adolescent girls who were attending their secondary education in high schools found in urban and rural areas of Sorro District were included in the study. However, those were severely ill and who had physical deformity at the time of data collection were excluded from the study.

\section{Data collection procedures}

Sample size was determined by using two population proportion formula for each specific objectives, was used by considering the following assumptions and finally the largest sample size was taken. The final sample size was 414. A multi stage sampling methods was employed to select the study subjects. Initially Sorro district was selected purposively. Then the high schools were stratified in to high schools resided in rural and urban areas and the sample size was allocated accordingly.

At the first stage there were two urban highs schools and eight rural high schools in Soro district. Then after three high schools were selected from rural setups by using simple random sampling method and the two high schools were taken from urban areas. Secondly, the sample size for high schools rural and urban settings was allocated proportion to population size allocated to size for each grades of selected high school and then to each sections of grade based on number of study subjects was found. Finally, simple random sampling of lottery methods was used to select study subjects from each section of grades by using students' roster as the sampling frame.

Structured questionnaire which were pretested in a high school out of those high schools selected for the study by considering $5 \%$ of the questionnaire. Anthropometric measurements like UNICEF portable electronic digital weight scale and Stadiometer with a moveable headboard (Hannover, Germany) were used to measure study subjects anthropometry. The data were collected by face to face interview and by taking anthropometric measurements through trained four female diploma nurses and supervised by two health officers. Moreover, the principal investigator monitored and coordinated the overall research activities.

A four-item adolescences food security scale, developed and tested in another study was used to assess adolescent girls food security status, the questions in the scale asked whether girls within the last month had (1) ever worried about having enough food, (2) ever had to reduce food intake because of shortage of food or lack of money to buy food, (3) ever had to go without eating because of shortage of food or money to buy food or (4) ever had to ask outside the home for food. Dietary diversity data were collected by asking participants the type of consumed in home or outside of compound in previous 24 hour before recall from nine food groups(38) [9].

\section{Operational definition}

Thinness - Adolescent girls whose BMI-for-age (BAZ) is below the $-2 \mathrm{Z}$-scores the median of the WHO reference population are considered as thin or acutely malnourished [10]

\section{Data Analysis Process And Procedure}


The data were entered on Epi-data version 3.1, cleaned, edited and were exported to SPSS for windows version 20 for analysis. BMI for age Z-score was analyzed by using WHO anthro plus software version 1.0.4(5) [5] and recoded into dichotomies a variable. Descriptive statistics including proportion, percentage, tables, graphs, frequency distribution, mean and standard deviation was used to describe the data. Principal component analysis was used assess household wealth status. Bivariate logistic regression analysis was done to see the association between individual explanatory and outcome variables with P-value $<0.25$ and to select candidates for multivariable binary logistic regression. Then finally, multivariable binary logistic regression model by using adjusted odds ratio (AOR) with $95 \%$ confidence interval $(\mathrm{Cl})$ was used to measure independent factors associated with outcome variables and P-value less than 0.05 was used to declare level of statistical significance.

\section{Results}

\section{Socio demographic and economic characteristics of study participants}

A total of 414 adolescent girls were participated in this study making the response rate of $100 \%$. The mean age were $(17.01 \pm 1.55)$ and $16.90 \pm 1.48, P=0.437)$ among adolescent girls in rural and urban high schools respectively. There was no significant difference in age between rural and urban students ( $\mathrm{P}$ value $=0.437)$. In both settings $197(95.2 \%)$ in rural areas and $189(91.3 \%)$ dominant ethnic group was Hadiya likewise protestant religion was also dominant in both settings $(85.5 \%$ in rural and $82.1 \%$ in urban) (Table 1). 
Table 1

Socio demographic and economic characteristics of adolescent girls attending high schools in rural and urban settings of Sorro district, Hadiya Zone, Southern Ethiopia, 2019

\begin{tabular}{|c|c|c|c|c|}
\hline \multirow[t]{2}{*}{ variables } & \multirow[t]{2}{*}{ Categories } & \multicolumn{2}{|c|}{ High schools } & \multirow{2}{*}{$\begin{array}{l}\text { Total } \\
(\mathrm{N}=414) \\
(\%)\end{array}$} \\
\hline & & $\begin{array}{l}\text { Rural } \\
(n=207) \\
(\%)\end{array}$ & $\begin{array}{l}\text { Urban } \\
(n=207) \\
(\%)\end{array}$ & \\
\hline \multirow[t]{2}{*}{ Age category } & $13-14$ & $10(4.8 \%)$ & $12(5.8 \%)$ & $22(5.3 \%)$ \\
\hline & $15-19$ & $\begin{array}{l}197 \\
(95.2 \%)\end{array}$ & $\begin{array}{l}195 \\
(94.2 \%)\end{array}$ & $\begin{array}{l}392 \\
(94.7 \%)\end{array}$ \\
\hline \multirow[t]{3}{*}{ Religion } & Protestant & )$^{177(85.5 \%}$ & )$^{170(82.1 \%}$ & $\begin{array}{l}347 \\
(83.8 \%)\end{array}$ \\
\hline & Orthodox & $6(2.9 \%)$ & $18(8.7 \%)$ & $24(5.8 \%)$ \\
\hline & Catholic & $24(11.6 \%)$ & $19(9.2 \%)$ & $43(10.4 \%)$ \\
\hline \multirow[t]{4}{*}{ Ethnicity } & Hadiya & $\begin{array}{l}197 \\
(95.2 \%)\end{array}$ & $\begin{array}{l}189 \\
(91.3 \%)\end{array}$ & $\begin{array}{l}386 \\
(93.2 \%)\end{array}$ \\
\hline & Amhara & $6(2.9 \%)$ & $10(4.8 \%)$ & $16(3.9 \%)$ \\
\hline & Kambta & $3(1.4 \%)$ & $6(2.9 \%)$ & $9(2.2 \%)$ \\
\hline & Others & $1(0.5 \%)$ & $2(1 \%)$ & $3(0.7 \%)$ \\
\hline \multirow[t]{2}{*}{ Family size } & $\leq 5$ & $23(11.1 \%)$ & $34(16.4 \%)$ & $57(13.8 \%)$ \\
\hline & $>5$ & $\begin{array}{l}184 \\
(88.9 \%)\end{array}$ & $\begin{array}{l}173 \\
(83.6 \%)\end{array}$ & $\begin{array}{l}357 \\
(86.2 \%)\end{array}$ \\
\hline \multirow[t]{3}{*}{ head of the $\mathrm{HH}$} & Father & $\begin{array}{l}188 \\
(90.8 \%)\end{array}$ & $\begin{array}{l}188 \\
(90.8 \%)\end{array}$ & $\begin{array}{l}376 \\
(90.8 \%)\end{array}$ \\
\hline & Mother & $14(6.8 \%)$ & $15(7.2 \%)$ & $29(7 \%)$ \\
\hline & Others & $5(2.4 \%)$ & $4(1.9 \%)$ & $9(2.2 \%)$ \\
\hline \multirow[t]{2}{*}{ Type of family } & Monogamy & $\begin{array}{l}189 \\
(91.3 \%)\end{array}$ & $\begin{array}{l}198 \\
(95.7 \%)\end{array}$ & $\begin{array}{l}387 \\
(93.5 \%)\end{array}$ \\
\hline & Polygamy & $18(8.7 \%)$ & $9(4.3 \%)$ & $27(6.5 \%)$ \\
\hline \multirow[t]{3}{*}{ Mothers educational status } & $\begin{array}{l}\text { No formal } \\
\text { education }\end{array}$ & $\begin{array}{l}131 \\
(63.3 \%)\end{array}$ & $62(30 \%)$ & $\begin{array}{l}193 \\
(46.6 \%)\end{array}$ \\
\hline & Formal education & $74(35.7 \%)$ & $\begin{array}{l}124 \\
(59.9 \%)\end{array}$ & $\begin{array}{l}219 \\
(52.9 \%)\end{array}$ \\
\hline & $\begin{array}{l}\text { Diploma and } \\
\text { above }\end{array}$ & $2(1 \%)$ & $21(10.1 \%)$ & $23(5.5 \%)$ \\
\hline Father's educational status & No formal & $86(41.5 \%)$ & $44(21.3 \%)$ & 130 \\
\hline
\end{tabular}




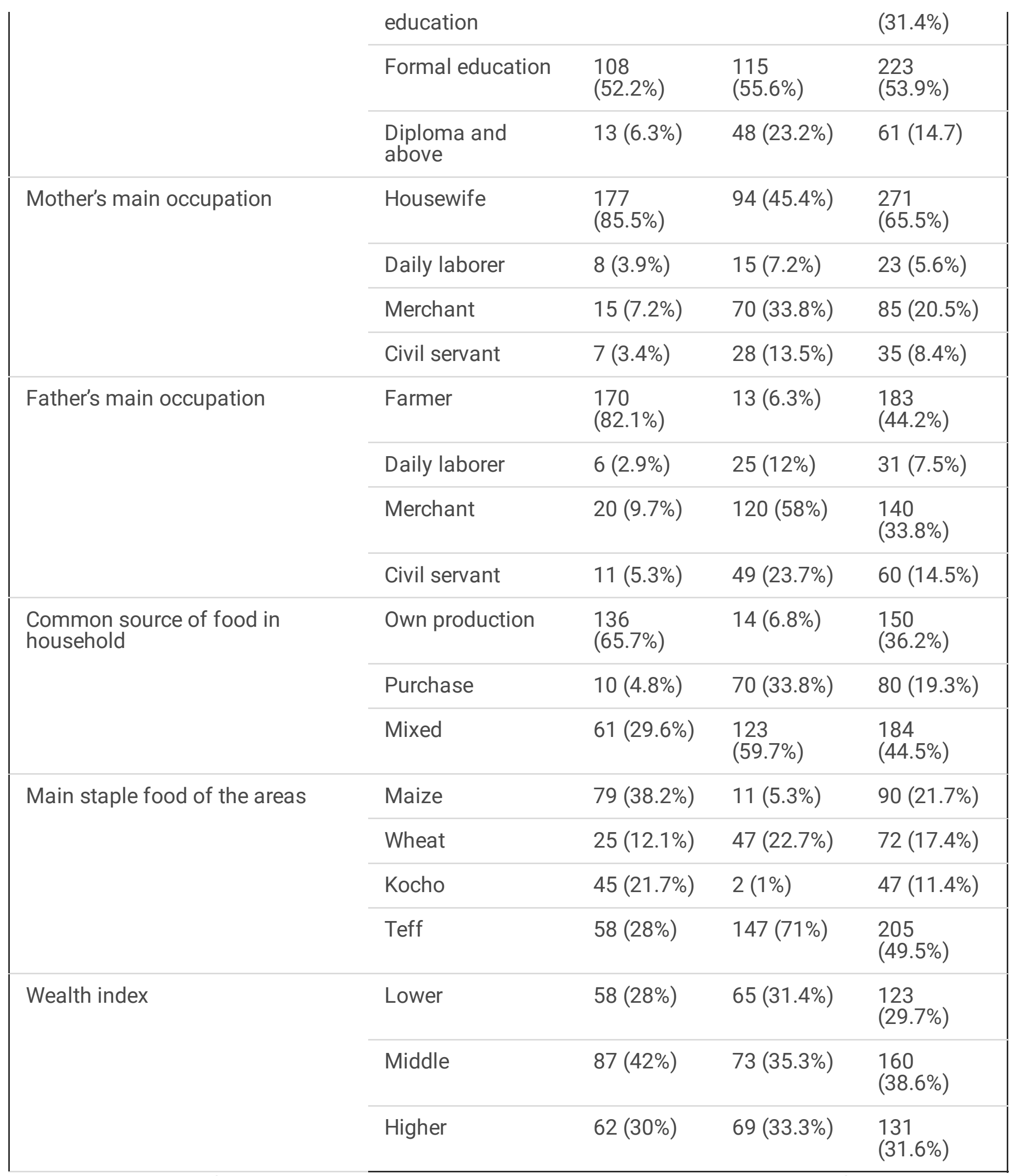

\section{Dietary and food security related characteristics of adolescent girls attending high schools}


In adolescents girls attending the education in rural area 78 (37.7\%) were food insecure while from urban areas $54(26.1 \%)$ of the study participants reported that they were food insecure in the past three months during the survey time. This study shows that there was statistical significant difference in adolescent

girls food security status between rural and urban areas $(P=0.011)$. The mean $(S D)$ of dietary diversity score was $3.72 \pm 1.01$ and $4.63 \pm 1.16$ in rural and urban areas respectively. More than three fourth $(79.7 \%)$ and less than half (43\%) of the adolescent girls from rural and urban areas had no adequate dietary diversity per day during survey time respectively. There was statistically significant difference concerning dietary diversity among students in high schools of rural and urban settings $(P=0.001)$. Grains or other starchy foods are the commonest foods eaten by adolescent girls both in rural and urban areas.

\section{The prevalence of thinness among adolescent girls attending high school}

The overall prevalence of the thinness among female adolescents attending high schools in Soro district, Hadiya Zone was $6.8 \%$. It was higher among students schooling in rural areas $18(8.7 \%)$ with $95 \%$ (Cl: $5.3-$ 12.6) than those in urban areas $10(4.8) 95 \%$ (Cl: $1.9-8.2)$. However there was no statistically significant difference in thinness among adolescent girls in rural and urban high schools.

\section{Factors associated with thinness among adolescent girls attending high schools}

Primarily bivariate binary logistic regression analysis was done between thinness and each explanatory variable to find factors associated with thinness. Accordingly family type, Place of residence, household wealth tertile, visiting health facility, main staple food of participants, source of drinking water, adolescent food security, availability of home latrine, hand washing practice, history of illness, meal frequency, skipping breakfast and individual dietary diversity were become a candidate variables for multivariable logistic model at P-value less than 0.25 .

Multivariable logistic regression analysis was done to identify independent predictors of thinness, consequently household wealth tertile, source of drinking water, dietary diversity and skipping breakfast were found to be an independent factors associated with thinness.

Adolescent girls attending high schools were found around four times higher odds of being thin (AOR: 4.19; $95 \%$ C.I: 1.13-15.47) in the low wealth tertile households as compared to those from households with higher Wealth tertile. The odds of being thin were more than two times higher among adolescent girls who use drinking water from unimproved source than adolescent girls who use drinking water from improved source (AOR: 2.31; 95\% C.I: 1.01-5.30). Similarly, adolescent girls who skip breakfast had around three times more odds of being thin than those students who did not skip breakfast (AOR: 2.97; C.I: 1.28-6.92). Finally, adolescent girls with inadequate dietary diversity were four times more likely to be thin than their counterparts who had adequate dietary diversity (AOR: 3.99; C.I: 1.15-13.82) (Table 2). 
Table 2

Factors associated with thinness among adolescent girls attending high schools in rural and urban setups in Soro district, Hadiya Zone, Southern Ethiopia, 2019

\begin{tabular}{|c|c|c|c|c|c|}
\hline \multirow[t]{2}{*}{ Variables } & \multirow[t]{2}{*}{ Categories } & \multicolumn{2}{|l|}{ Thinness } & \multirow{2}{*}{$\begin{array}{l}\text { Crude OR } \\
95 \% \text { [C.I] }\end{array}$} & \multirow{2}{*}{$\begin{array}{l}\text { Adjusted OR } \\
\text { [95\% C .I] }\end{array}$} \\
\hline & & Thin & Normal & & \\
\hline \multirow[t]{3}{*}{ Wealth index } & Low & $\begin{array}{l}14 \\
(11.4 \%)\end{array}$ & $\begin{array}{l}109 \\
(88.6 \%)\end{array}$ & $\begin{array}{l}5.48(1.54- \\
19.57) \star\end{array}$ & $\begin{array}{l}4.19(1.13- \\
15.49) *\end{array}$ \\
\hline & Middle & $11(6.9 \%)$ & $\begin{array}{l}149 \\
(93.1 \%)\end{array}$ & $\begin{array}{l}3.15(0.86- \\
11.54)\end{array}$ & $\begin{array}{l}3.09(0.82- \\
11.64)\end{array}$ \\
\hline & High & $3(2.3 \%)$ & $\begin{array}{l}128 \\
(97.7 \%)\end{array}$ & 1 & 1 \\
\hline \multirow[t]{2}{*}{ Source of water } & Unprotected & $15(13 \%)$ & $100(87 \%)$ & $3.30(1.52-7.18) *$ & $2.31(1.01-5.30) *$ \\
\hline & Protected & $13(4.3 \%)$ & $\begin{array}{l}286 \\
(95.7 \%)\end{array}$ & 1 & 1 \\
\hline \multirow[t]{2}{*}{$\begin{array}{l}\text { Skipping } \\
\text { breakfast }\end{array}$} & yes & $\begin{array}{l}15 \\
(16.3 \%)\end{array}$ & $\begin{array}{l}77 \\
(83.7 \%))\end{array}$ & $4.6(2.12-10.14)^{*}$ & $2.98(1.28-6.92) *$ \\
\hline & No & $13(4 \%)$ & $309(96 \%))$ & 1 & 1 \\
\hline \multirow[t]{2}{*}{ Dietary diversity } & inadequate & $\begin{array}{l}12 \\
(12.9 \%)\end{array}$ & $81(87.1 \%)$ & $2.52(1.13-5.58) *$ & $\begin{array}{l}3.99(1.15- \\
13.82)^{\star}\end{array}$ \\
\hline & Adequate & $16(5 \%)$ & 305 (95\%) & 1 & 1 \\
\hline
\end{tabular}

\section{Discussion}

This study was aimed on studying the prevalence and factors associated thinness among adolescent girls attending high schools in rural and urban soro district, Hadiya Zone, Southern Ethiopia. It was higher among students schooling in rural areas $18(8.7 \%)$ with $95 \%$ (Cl: 5.3-12.6) than those in urban areas 10(4.8) 95\% (Cl: 1.9 - 8.2) even though there was no statistically significant difference. Household wealth tertile, source of drinking water, dietary diversity and skipping breakfast were found to be independent factors associated with thinness among adolescent girls attending high school.

The prevalence of thinness was higher in rural area (8.7\%) than that of urban area (4.8\%) even though it was not statistically significant. These might be the current study found that there was statistical significant difference between two settings in terms of educational and occupational status of parents, household chores, source of drinking water, adolescent food security status and dietary diversity. The finding was in line with other comparative studies reports in Northern Ethiopia, South-Western Ethiopian, India and Pakistan [11-14]. 
Adolescent girls attending high schools had found to be four times higher odds of being thin in the low households' wealth tertile as compared to those from high households Wealth tertile. The finding was consistent with study conducted in Aksum town and Jimma zone, Ethiopia $[15,16]$. This could reflect the fact that the higher the household wealth, it enables households to access different foods and to get services that improve the nutritional status of adolescents.

The current study revealed that the source of drinking water among high schools adolescent girls was independent factor of thinness. The odds of being thin were more than two times higher among adolescent girls who drink water from unimproved source as compared to adolescent girls drink water from improved source which agrees with study conducted in Adwa, northern Ethiopia [17]. This could be because of fact that the use of unimproved source of drinking water is vehicle for intestinal parasites and water borne diseases which leads to vicious cycles of undernutrition and disease. Besides, those adolescent girls who skip breakfast were more likely to be thin than their counterparts who did not skip their breakfast. It is in line with the study from Wolaita Sodo, Southern Ethiopia [18].

Adolescent girls being thin was four times more likely higher among high school adolescent girls who did not get adequately diversified food as compared to high schools adolescent girls who get adequately diversified food. The finding agrees with studies which were conducted in different parts of Ethiopia like Adama city, Jimma Zone, south west Ethiopia, rural Tigray region and bale zone [19-23]. This might be due to the fact that increased demands of nutrients during adolescent period could lead to thinness if dietary diversity is inadequate.

This study has its own limitations. The recall bias might be happened for assessing the type of foods eaten by adolescents to determine the dietary diversity among them. Obtaining the exact age of the students were challenging due to not knowing the birth date, however, every options were used to estimate the age of the eligible subjects for the study. Besides, the nature of the study, cross sectional has weakness of not determining the causation in the study.

\section{Conclusion}

The prevalence of the thinness among adolescent girls from rural high schools was higher which is not going in line with the international recommendations on the nutritional status of adolescents. Being low in household wealth tertile, unprotected source of drinking water, inadequate dietary diversity and skipping breakfast were those factors identified to be independently associated with thinness among female adolescents. Attention should be given from government and nongovernmental organizations by empowering household economic capacity, extending access for pure drinking water and increasing nutrition sensitive agriculture focusing on maintaining food varieties. Creating awareness for adolescent girls not to skip their breakfast is one of the essential activities to be done. In the future, further studies shall be done to realize the real cause of the thinness among adolescents by using strong study designs.

What is already known on this topic? 
- The prevalence of thinness among adolescent girls was 8.4\% according to EDHS 2016 Ethiopia

- Thinness among adolescents is one of the challenging nutritional issues in lifecycle approach in Ethiopia and the area that does not get attention.

What this study adds?

- This identified the disparity between rural and urban adolescent girls attending the high schools in southern part of the Ethiopia.

- The study might fill the information gap depending on the nutritional status of the adolescent girls

\section{Declarations}

\section{Acknowledgment}

We would like to thank data collectors, supervisors and respondents for their contribution.

\section{Availability of data and material}

The datasets are available from the corresponding author on reasonable request.

\section{Authors' contribution}

DA and TB conception and study design, DA Overall supervision of data collection, DA,TB, BZ Data analysis and interpretation, TT Manuscript preparation. All authors approved final version of the manuscript.

\section{Funding}

This study was funded by Gombora district disaster Preparedness and Food Security office.

\section{Competing interest}

The authors declare that they have no competing interests.

\section{Consent for publication}

Not applicable.

\section{Ethical approval and consent to participate}

Ethical clearance was obtained from the Jimma University, Institute of Health Ethical review board. The letter of cooperation was written for Sorro District's selected high schools under soro district education office in order to proceed the study. The study was conducted based on voluntary participation by study subjects after explaining the purpose of study. Informed consent was obtained from each participant before starting the interview without any obligation or persuading. Anyone had right to withdraw from 
interview at any time without any harm. No name of participant has been written and code was used and confidentiality of data was assured for participants.

\section{References}

1. WHO. Nutrition in adolescence - Issues and Challenges for the Health Sector [Internet]. 2005. Geneva. (ISBN 924159366 0). Report No.: WS 115. Available from: available from .who.int accessed date $25 / 12 / 2018$

2. Silva WI De. Emerging Reproductive Health Issues Among Adolescents in Asia [Internet]. Vol. 02115. 1998. Available from: available from www.ncbi nlm.nih.gov, accessed date 18/12/2018.

3. Truebwasser U. landscape analysis on adolescent health and nutrition in Ethiopia. Addis Abeba; 2017.

4. Bocquenet G, Chaiban T, Cook S, Escudero P, Franco A, Romo CG. A fair chance for every child [Internet]. 2016. Available from: data.unicef.org

5. WHO. WHO AnthroPlus for Personal Computers Manual Software for assessing growth of the world ' s children [Internet].2009. Geneva. Available from: http://www.who.int/growthref/tools/en/ accessed date 12/2/2019

6. Benedict RK, Schmale A. adolescent nutrition 2000-2017: dhs data on adolescents age 15-19 dhs comparative. Rockville, Maryland, USA: ICF. 2018. Available from: www.dhsprogram.com accessed date $13 / 1 / 2019$

7. Keats EC, Rappaport A, Jain R, Oh C, Shah S, Zulfiqar A. Diet and Eating Practices among Adolescent Girls in Low- and Middle-Income Countries. 2018. Available from: .

8. Soro district finance and economic office annual report.2018

9. FAO. Guidelines for measuring household and individual dietary diversity. ROME; 2011.

10. Onis M De, Onyango AW, Borghi E, Siyam A, Siekmann J. Development of a WHO growth reference for school-aged children and adolescents. 2007;85(9):660-7.

11. Maiti S, Km A, Tk B, Ghosh D, Paul S. A Comparative Study on Nutritional Status of Urban and Rural Early A Comparative Study on Nutritional Status of Urban and Rural Early Adolescent School Girls of West Bengal, India. 2011 Available from: https://www.researchgate.net/publication/273013190\%0A accessed date 17/1/2019

12. Berheto TM, Mikitie WK, Argaw A. Urban-rural disparities in the nutritional status of school adolescent girls in the Mizan district, south- western Ethiopia. Rral Remote Heal [Internet]. 2015;1-10. Available from: / www.rrh.org.au accessed date 25/01/2019

13. Anwer I AJ. Nutitional status comparison of rural with urban school children in Faisalabad District, Pakistan. Rural Rmote Heal. 2003;9.

14. Herrador Z, Sordo L, Gadisa E, Moreno J, Nieto J, Custodio E, et al. Cross-Sectional Study of Malnutrition and Associated Factors among School Aged Children in Rural and Urban Settings of Fogera and Libo Kemkem Districts, Ethiopia. 2014;9(9):1-11. 
15. Kalkidan Hassen, Getu Gizaw and TB. Dual Burden of Malnutrition Among Adolescents of Smallholder Coffee Farming Households of Jimma Zone, Southwest Ethiopia. 2017;38(2):196-208.

16. Aregawi Amha TG. Prevalence and Associated Factors of Thinness among Adolescent Girls Attending Governmental Schools in Aksum Town, Northern Ethiopia. Med J Dr DY Patil Vidyapeeth. 2018;

17. Gebregyorgis T, Tadesse T, Atenafu A. Prevalence of Thinness and Stunting and Associated Factors among Adolescent School Girls in Adwa Town, North Ethiopia. Int J Food Sci. 2016;2016:19.

18. Teferi DY, Atomssa GE, Mekonnen TC. Overweight and Undernutrition in the Cases of School-Going Adolescents in Wolaita Sodo Town, Southern Ethiopia. J Nutr Metab. 2018;10.

19. Mulugeta A, Hagos F, Stoecker B, Kruseman G, Linderhof V, Abraha Z. Nutritional Status of Adolescent Girls from Rural Communities of Tigray, Northern Ethiopia. EthiopJHealth Dev. 2011;2389.

20. Assefa H, Belachew T, Negash L. Socioeconomic Factors Associated with Underweight and Stunting among Adolescents of Jimma Zone, South West Ethiopia : A Cross-Sectional Study. ISRN Public Health. 2013;

21. Roba KT, Abdo M WT. Nutritional Status and Its Associated Factors among School Adolescent Girls in Adama City, Central Ethiopia. J Nutr Food Sci. 2016;6(3):4-11.

22. Mohammed AY, Tefera TB. Nutritional Status and Associated Risk Factors Among Adolescent Girls in Agarfa High School, Bale Zone, Oromia. Int J Nutr Food Sci. 2015;4(4):445-52.

23. Wolde T, Tessema TB, Ejeta E. Nutritional Status of Adolescent Girls Living in Southwest of Ethiopia. Food Sci Qual Manag. 2014;34. 